\title{
The Research of University-industry Knowledge Innovation Alliance based on Actor Network Theory
}

\author{
Jian-feng Shi, Qing-pu Zhang \\ School of Management Harbin Institute of Technology Harbin, Heilongjiang Province, China
}

\begin{abstract}
University-industry knowledge innovation alliance, a new form of university-industry cooperation. The paper explores this kind of alliance based on actor-network theory. It builds a different nature actor-network which contains enterprise, university, institute, government, resource and the concepts to explain the alliance's mechanism. Some appropriate solutions are proposed that may be encountered in the cooperating process. It stresses that the alliance's internal network should be strengthened with the external environment, so as to improve the performance of alliance and achieve the desired goals.
\end{abstract} alliance

Index Terms -ANT, university-industry knowledge innovation

\section{Introduction}

"joint development of university-industry research projects" policy in China was implemented from 1990s, and in the 21st century, university-industry cooperation began to spring up. With the rapid development of science and technology, the traditional research cooperation is facing increasingly complex environment. In the past, two or three parties can form a coalition, but now an alliance maybe consist of more partners, and then the cooperation becomes increasingly complex. Significant knowledge, technology and innovation, inventions can not be realized through conventional research cooperation. In addition, with the escalation of internet technology, big data technology and cloud computing are changing the external R\&D environment, and the research cooperation has many new challenges. Internal members diversified demands of diverse interests, and the complexity of the problems facing both internal and external environment both brought new problems and opportunities. In this context, as an advanced form of research cooperation, university-industry knowledge innovation alliance came into being. The university-industry knowledge innovation alliance takes knowledge as ties, knowledge innovation as the goal, in accordance with the prior agreement, the different independent economic actors share the resources required in knowledge innovation activities, undertake the risks and gain the earnings of knowledge innovation. Each alliance partner learn and achieve knowledge innovation in the network, and then enhance their core competitiveness.

Compared to traditional research cooperation, the university-industry knowledge innovation alliance has more uncertainty, because their cooperation objectives usually involves technical forefront of industrial development, and pursues breakthrough innovations in the field of new technologies[1-2], so the cooperation mechanism is more complex, exploring its cooperation mechanism can help understand this phenomenon correctly, and provide intellectual support for the development of relevant research cooperation policy.

In this study, we will discuss this kind of universityindustry knowledge innovation alliance which are in the open market, with organizational spontaneity not organized by governments, and enterprises as the alliance initiators.

\section{Actor Network Theory}

In the mid 1980s, the Paris School which belonged to scientific knowledge sociology, and the French sociologists Latour, Caron and labor were the core people. They analyzed "internal" and "external", "knowledge" and "social", "macro" and "micro" problems on laboratory research experience. With combining laboratory anthropological research and poststructuralism in France, they proposed a new research program, named actor-network theory (referred to ANT) [3-4].

ANT reveals the complexity of contemporary scientific knowledge production process and the constitution of the organization, and re-established the status and role of the constituent elements in knowledge production systems. According to ANT, natural, social and human achievements of all activities are constructed out of a variety of network containing heterogeneous actors. While ANT from the field of scientific knowledge sociology, but as an analytical framework and a systematic approach, it can be extended to other areas of human behavior. Currently, ANT has gained more and more attention by academia, and are applied to economics, management, education, human geography, and many other fields [5-7].

\section{The Elements of University-industry Knowledge Innovation Alliance}

ANT advocates that social and technical knowledge is a heterogeneous network consists of human and non-human actors. In the heterogeneous network, whether it is human actors and non-human actors are intertwined and integrated with each other with equal status. The significance lies in their presence is to establish contact between the other actors. If they are isolated, it does not make sense. The heterogeneity of university-industry knowledge innovation alliance network performances that all the main actors involved in the network are heterogeneous and reflect the differences in the interests and the orientation behavior of the various actors. The human actors in the university-industry knowledge innovation alliance include: enterprise actors, university actors, institute actors, the 
relevant government departments and the market demander. Non-human actors include two types, matter and consciousness category.

Enterprise actors in university-industry knowledge innovation alliances are the initial driver and policy makers, and they are called for the mobilization role in the formation and development of the network. Firstly, according to the market feedback, enterprise actors determine the next direction of research and development, if they find that they can not finish the job by themselves or the cost is too higher, they will seek for outside help. Next, the enterprises need to find partners, they will examine the partners' reserve of knowledge, talent situation and so on, then discuss the cooperation content. Finally, the parties reach a collaboration and make cooperation documents to establish research program of action for the university-industry knowledge innovation alliance, then the project team begin deploying every partner's task. Enterprises provide facilities, funding, management and R\&D personnel, universities and institutes provide knowledge, technology, science and technology talent, government and markets consumer are indirect stakeholders. The government is responsible for the formulation and interpretation of the relevant science and technology policy, building a platform, providing necessary financial support, the consumers identify the innovative achievements created by the alliance, and give the feedback with its unique way. All of these human actors work together to implement and execute the university-industry knowledge innovation alliance's task.

Among the non-human actors, matter actors mainly refer to the scope of the experimental hardware, software, capital, technology and knowledge; consciousness actors mainly refer to the scope of needs of the parties in the coalition, policies and text and so on. The laboratory hardware and software in matter scope are the tools and platforms to bear universityindustry knowledge innovation alliance, only they are utilized fully, the alliance's level can be reflected correctly. Capital funding can maintain the normal operation of the network, including R\&D facilities construction funds, working capital and others. Consciousness demand includes the demand of market competition, intellectual property needs, personnel training, etc., which are the major power source and boosters to form the university-industry knowledge innovation alliance. Policies and systems, including text and technology policy, cooperation contracts, resolutions, planning, assessment system, incentives and disincentives, response measures. These are the tools that human actors used to promote the alliance's development, constraint cooperation, and be the power to implement policies and pursuit interests. By writing records and language expression, these non-human actors expose the meaning of the alliance's interests, therefore they must be incorporated into the research actors of the university-industry knowledge innovation alliance network.

\section{Operation of University-industry Knowledge Innovation Alliance}

After clearing various types of actors that are included in the alliance, the most important process is translation. Translation is a key in ANT theory, it's task is definite the respective roles of the network. Figure 1 is the translational research process of university-industry knowledge innovation alliance's actors network. With translation activities, actors constitute a network, the translational process includes issues presented, recruiting members, organization and mobilization these three key links.

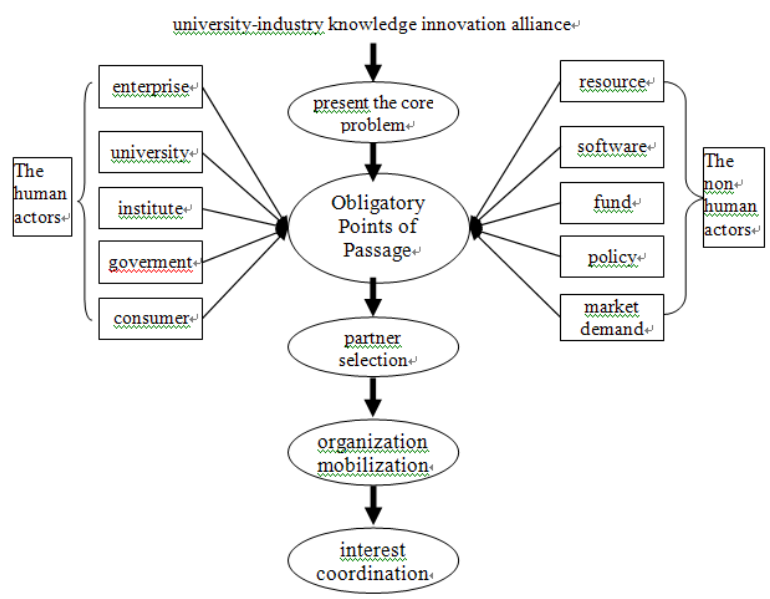

Figure 1 translational research actors in the process of university-industry knowledge innovation alliance Network

\section{A. Present the Core Problem}

In the knowledge innovation alliance operation process, every actor will face corresponding difficulties. To successfully complete the transfer process, the various actors will exclude their own obstacle firstly. ANT actors named this theory that overcoming their own obstacles Obligatory Points of Passage (OPP). OPPs are the key issues to be addressed in the process of constructing the network, the OPPs will clearly define mandatory action objectives of the alliance.

It seems that the common problems faced by the university-industry knowledge innovation alliance network actors is: how to generate new knowledge, new technology as soon as possible? In fact, in the course of the league, each of the actors face different difficulties, to successfully complete the transfer process, the various actors should exclude their obstacles. On the enterprise's side, whether the pre-market research is adequate, production facilities can meet the needs, financial support are enough? All of these problems are a series of issues to consider. For universities and research institutes, they should consider the knowledge and ability of qualified personnel, whether they have the capacity to produce knowledge, innovation knowledge, the new knowledge can be transformed into productive forces and was recognized by the market and other issues. All of these constitute the OPPs to influence and enhance the university-industry knowledge innovation alliance's development. 


\section{B. Partner Selection}

From the ANT perspective, university-industry knowledge innovation alliance is a heterogeneous network, all human actors and non-human actors in the network are the nodes, these nodes connect with others, each node has its own specific task and is indispensable. To ensure this heterogeneous network working properly, selecting nodes correctly is essential.

To human actors, the partners selection is usually by two ways that governments set up service platform and the partners find each other by themselves. Lu et al[8] found that partner selection in the research, the following four factors play a key role: the technical level of cooperative R\&D partners, the level of resources to research and development, cooperation ability, the level of intellectual property. For the partner selection of university-industry knowledge innovation alliance, the level of cooperation related to intellectual property is more important.

ANT theory suggests that the role of the human actors are symmetrical with the role of non-human actors, previous studies have focused on "people", and the observation of nonhuman actors is less. Among non-human actors in the university-industry knowledge innovation alliance networks, whether material aspects of the experimental hardware, software, or a sense of the scope of the market demand of funds, policies and systems are directly determines to the success or failure of alliances and cooperation. So when the league was first established, it should be pay more attention to the above factors, which are often easily overlooked in practice.

\section{Organization and Mobilization}

To ensure the smooth running of the organization, before establishment, the university-industry knowledge innovation alliance must be fully mobilized. In this process, coordinating the interests of all members is the main content. For example[9], in 2012, the first prize of the national scientific and technological progress, up to 30 units of the Senate inquiry, involving 18 companies, 10 research institutes, 2 universities, mainly to complete personnel 50 , such a largescale research cooperation in the past is very rare. Units involved in a wide range of participants in many cases, how to coordinate the interests of the parties is the most important problem to resolve in the mobilization process.

According to ANT theory, the formation of universityindustry knowledge innovation alliances' interest relation depends on functional orientation and integration of interests between the various heterogeneous network of internal actors. The alliance's benefits achieved through game and negotiation between actors. In the implementation process of university-industry knowledge innovation alliances, the actors are not consistent with their location of the work, but they should form a coordinated partnership. Only the various actors are equal, the alliance can carry out effective integration. The process to obtain the interests of all parties needs actors to resolve conflicts and to coordinate the relationship between each other. According to ANT, every actor in the network has its own ability to act with consideration of their interests. Actors ensure the stability of the network by constantly coordinate the interests. Coordination in the organization ensure the work efficiency, and the coordination between people and material determines the development of scientific knowledge[10].

\section{Conclusion}

ANT theory regards synergistic value between factors in the network as important, these factors include "human" and "non-human", it is essentially different between the traditional that usually focus on the study of human factors. Through the exploration of the non-human actors, it will enhance people's understanding of non-human actors, and it is conducive to connect each node in the network, then it will promote knowledge transfer and innovation. In addition, as a social science research methods, ANT theory also emphasizes the internal network to actively interact with the external network for knowledge innovation and research alliances, any one of inventions, knowledge innovation should go through market testing, social acceptance, without society this environment, any research in the laboratory can only be shelved, should not be transferred into productivity. Thinking the rapid development of science and technology, only society demand and market information are fully known, the universityindustry knowledge innovation alliance can show their strengths, and create maximum benefits for all parties.

\section{Acknowledgment}

This research is part of the "Research of universityindustry cooperation" project, with support from "Shandong province humanities and social science research project for institutions in 2014(No.J14WG70)".

\section{References}

[1] Mora-Valentin EM, Montoro-Sanchez A, Guerras-Martin L A. Determining factors in the success of $\mathrm{R} \& \mathrm{D}$ cooperative agreements between firms and research organizations RESEARCH POLICY 2004, 33 (1): 17-40.

[2] Mohnen P, Hoareau C. What type of enterprise forges close links with universities and government labs Evidence from CIS 2 Managerial and Decision Economics 2003, 24 (2-3):133-145.

[3] GUO Jun-li. Actor-Network Theory of Paris School and Analysis of Philosophical Significance. Studies in Dialectics of Nature. 2007(02): 104-108.

[4] LIU Zhou. 'M-C-K' Group Actor Network Model and Knowledge Production Mechanism of Interdisciplinary Innovation Team. Science of Science and Management of S.\& T. 2012(03): 158-164.

[5] Callon M. Actor-network theory - the market test Actor network theory and after 1999: 181-195.

[6] Steen J. Actor-network theory and the dilemma of the resource concept in strategic management Scandinavian Journal of Management 2010, 26 (3): 324-331.

[7] Fenwick T, Edwards R. Introduction: Reclaiming and renewing actor network theory for educational research Educational Philosophy and Theory 2011, 43 (s1): 1-14.

[8] LU Yan, TANG jian-ying, HUANG Rui-hua. The Empirical Study on the Factors in Selecting Cooperative. R\&D Management. 2006(01): 5258.

[9] http://www.most.gov.cn/ztzl/gjkxjsjldh/index.htm3, $2013 \mathrm{~m} 1$.

[10] Gao Fu-rong. Constructing Analysis of Rural Informatization Projects Based on the Actor-network Theory. Science On Society. 2013(02): 110-121. 